REFERENCES:

[1] Foster $\mathrm{H}$, et al. Outcome in adults with juvenile idiopathic arthritis: A quality of life study. Arthritis \& Rheumatism. 2003;48(3):767-775

[2] Kontodimopoulos N, et al. Validity of SF-12 summary scores in a Greek general population. Health Qual Life Outcomes. 2007 Sep 28;5:55

[3] Minden $\mathrm{K}$, et al. Long-term outcome in patients with juvenile idiopathic arthritis. Arthritis \& Rheumatism. 2002;46(9):2392-2401

[4] Anink J, et al. Long-term quality of life and functional outcome of patients with juvenile idiopathic arthritis in the biologic era: a longitudinal follow-up study in the Dutch Arthritis and Biologicals in Children Register. Rheumatology. 2015;54(11):1964-1969

Disclosure of Interest: None declared

DOI: 10.1136/annrheumdis-2018-eular.6604

\section{AB1096 OBSERVATIONAL SAFETY STUDY OF GOLIMUMAB IN TREATMENT OF POLYARTICULAR JUVENILE IDIOPATHIC ARTHRITIS USING THE GERMAN BIOLOGICS JIA REGISTRY}

G. Horneff ${ }^{1,2}$, A. Klein ${ }^{1}$, on behalf of BIKER registry working group. ${ }^{1}$ ASKLEPIOS, Sankt Augustin; ${ }^{2}$ University of Cologne, Cologne, Germany

Background: Golimumab (GLM) received European marketing authorisation for treatment of polyarticular JIA (pJIA). The long-term safety of GLM in clinical preactice has not been characterised.

Objectives: The aim of the present project is to conduct a post-authorisation safety study to monitor long-term safety of subcutaneous GLM in the treatment of pJIA in routine clinical practice setting.

Abstract AB1096 - Table 1

\begin{tabular}{|c|c|c|c|c|c|}
\hline Cohort & $\left({ }^{1} \mathrm{GOL}\right.$ & $\begin{array}{c}\left({ }^{2} \text { concurrent }\right. \\
\text { TNFi (ETA/ADA) }\end{array}$ & $\begin{array}{c}\left({ }^{3} \text { concurrent }\right. \\
\text { MTX }\end{array}$ & $\begin{array}{c}\left({ }^{4} \text { historic }\right. \\
\text { TNF }\end{array}$ & $\begin{array}{l}\left({ }^{5} \text { historic }\right. \\
\text { MTX }\end{array}$ \\
\hline n & 18 & 53 & 13 & 2103 & 1517 \\
\hline Age, median [IQR] & $\begin{array}{c}13.9 \\
{[12.8 ; 15.2]}\end{array}$ & $11.6[7.9 ; 14.8]$ & $\begin{array}{c}10.5 \\
{[4.6 ; 12.6]}\end{array}$ & $\begin{array}{c}12.7 \\
{[8.9 ; 15.5]}\end{array}$ & $\begin{array}{c}10.2 \\
{[5.6 ; 13.9]}\end{array}$ \\
\hline $\begin{array}{l}\text { Disease duration, } \\
\text { median [IQR] } \\
\text { Pretreatment }\end{array}$ & $\begin{array}{c}8.0 \\
{[2.5 ; 11.4]}\end{array}$ & $2.6[0.9 ; 6.5]$ & $0.2[1.1 ; 0.6]$ & $\begin{array}{c}3.0 \\
{[1.1 ; 5.8]}\end{array}$ & $\begin{array}{c}0.9 \\
{[0.4 ; 2.8]}\end{array}$ \\
\hline NSAID, $\mathrm{n}(\%)$ & $16(89)$ & $44(83)$ & $11(85)$ & $1886(90)$ & $\begin{array}{l}1293 \\
(85.2)\end{array}$ \\
\hline $\begin{array}{l}\text { Steroids systemic, } \\
\mathrm{n}(\%)\end{array}$ & $10(56)$ & $27(51)$ & $5(38)$ & $1030(49)$ & $\begin{array}{c}315 \\
(20.7)\end{array}$ \\
\hline MTX, n(\%) & $18(100)$ & 49(92) & & $1794(85)$ & \\
\hline $\begin{array}{l}\text { other DMARDs, n } \\
(\%)\end{array}$ & $7(39)$ & $4(8)$ & 0 & $636(30)$ & $143(9.4)$ \\
\hline $\begin{array}{l}\text { Biologics } \\
\text { Concomitant }\end{array}$ & $14(78)$ & $17(36)$ & 0 & $226(11)$ & 0 \\
\hline Treatment & & & & & \\
\hline NSAID, n(\%) & $8(44)$ & 38 (72\%) & $12(92)$ & $1544(73)$ & $\begin{array}{l}1394 \\
(91.9)\end{array}$ \\
\hline $\begin{array}{l}\text { Steroids systemic } \\
\mathrm{n}(\%)\end{array}$ & 0 & $11(21 \%)$ & $4(31)$ & $619(29)$ & $\begin{array}{l}359 \\
(23.7)\end{array}$ \\
\hline MTX, n(\%) & $13(72)$ & $39(74)$ & $13(100)$ & $1389(66)$ & $\begin{array}{l}1517 \\
(100)\end{array}$ \\
\hline $\begin{array}{l}\text { other DMARD,s n } \\
(\%)\end{array}$ & 0 & 0 & 0 & $233(11)$ & $57(4)$ \\
\hline $\begin{array}{l}\text { Baseline Disease } \\
\text { Activity }\end{array}$ & & & & & \\
\hline $\begin{array}{l}\text { Active joints, } \\
\text { median [IQR] }\end{array}$ & $5[2 ; 6]$ & $4[2 ; 9]$ & $9[7 ; 13]$ & $3[1 ; 7]$ & $3[2 ; 7]$ \\
\hline $\begin{array}{l}\text { Phys Global, } \\
\text { median [IQR] }\end{array}$ & $37[19 ; 56]$ & $33[24 ; 49]$ & $59[43 ; 75]$ & $\begin{array}{c}48 \\
{[26 ; 71]}\end{array}$ & $\begin{array}{c}43 \\
{[24 ; 67]}\end{array}$ \\
\hline $\begin{array}{l}\text { JADAS_10, } \\
\text { median [IQR] }\end{array}$ & $12[6 ; 16]$ & $12[8 ; 16]$ & $21[18 ; 24]$ & $13[8 ; 18]$ & $13[8 ; 18]$ \\
\hline
\end{tabular}

Methods: Monitoring of GLM in 200 pts with polyarticular JIA (cohort 1) in clinical practice will be performed by the German BiKeR Registry compared to a concurrent cohort 2 with 400 pts newly treated with alternative (approved) TNF-inhibitor, a concurrent cohort 3 with 500 pts newly starting methotrexate, a historic cohort 4 of patients treated with TNF-inhibitors and a historic cohort 5 never exposed to biologics but treated with methotrexate. Efficacy will be assessed by single disease activity markers and JADAS10, safety will be assessed by adverse event reporting and monitoring with a special interest on serious infections including opportunistic infections and TB, malignancies, autoimmune processes and exposure during pregnancy.

Results: Recruiting of three new cohorts 1-3 started in July 2017. Historic control cohorts 4 and 5 were obtained from the BIKER data base. Cohort 4 was recruited from 2006 to 2016, cohort 5 from 2005 to 2011. Baseline patients' characteristics are outlined in table 1. So far, patients of the GLM cohort 1 were older, had a much longer disease duration and received pre-treatment with other biologics more often. All patients in this cohort received combination with methotrexate. Since so far GLM is approved for children with body weight of at least $40 \mathrm{~kg}$ and in combination with methotrexate, differences were expected. Baseline disease activity indicators are within the range of alternative TNF inhibitors and the historic cohor 4 while patients of the concurrent methotrexate cohort receiving their first treatment approach had the highest baseline disease activity.

Conclusions: The BiKeR registry has been collecting data from JIA patients treated with approved biologics in routine clinical practice since 2001. To provide context for interpreting long-term safety and effectiveness of data for GLM, analysis will also include data from contemporary pJIA patients treated with alternative TNF inhibitors and methotrexate.

Acknowledgements: This project of the BIKER registry is supported by an unrestricted grant from MSD, Germany

Disclosure of Interest: None declared

DOI: 10.1136/annrheumdis-2018-eular.2165

\section{AB1097 PROGRESSIVE PSEUDORHEUMATOID DYSPLASIA (PPRD) IN SIBLINGS MIMICKING INFLAMMATORY ARTHROPATHY}

S. Khan ${ }^{1}$, Z. Afridi ${ }^{2}$, I. Malik ${ }^{1} .{ }^{1}$ Rheumatology; ${ }^{2}$ Pediatrics, Lady Reading Hospital, Medical Teaching Institution, Peshawar, Pakistan

Background: Progressive pseudorheumatoid dysplasia is a rare condition with an incidence of 1 in 1 million.

Objectives: Keeping in mind rare disorders when dealing with children in rheu matology clinics.

Methods: A 12 years old girl was referred to rheumatology by general practitioner. Her main complaint was difficulty walking, standing up from sitting position, short stature and nodulosis of interphalangeal joints. Initially she had muscle weakness which was thought to be contributing to her gait problem and difficulty standing.

Investigation revealed myopathic changes on electromyography though her CK was entirely normal. Other investigations including routine bloods and inflammatory markers were normal. Immunology was negative. X-rays revealed reduced joint spaces in interphalangeal joints and epiphyseal dysplasia in elbows and hips. On examination there was no evidence of any synovitis. The child was of short stature i.e less than the 3rd percentile on growth chart. She had a waddling gait. There was nothing in the history to suggest previous or current inflammatory arthropathy.

Interestingly this child had another younger sibling, 7 years old girl who had similar changes in her hands.

Results: Based on history, investigations, examination and familial characteristic we felt that these two kids (siblings) had PPRD. It usually happens at the age of 3 to 8 years. Walking pattern, fatigue, weakness and intermittent episodes of stiffness are the common symptoms. Other feature is reduced joint spaces in knees and hips. At birth kids are usually of normal height but by adulthood they are short statured. They also can have calcium deposition around the joints. PPRD is caused by mutation in WISP3 gene which is responsible for bone growth and cartilage maintenance and is inherited in an autosomal recessive pattern.

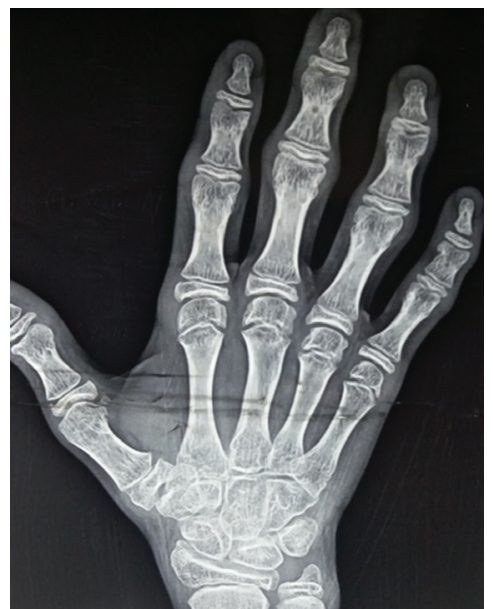

Abstract AB1097 - Figure 
Conclusions: Kids can have a variety of musculoskeletal disorders. We feel that management of rheumatological conditions in kids need to be approached in a multidisciplinary way. Genetic disorders mimicking inflammatory conditions need to be considered all time. In those places particularly where paediatric rheumatologists are not available, involvement of paediatricians may be useful. In terms of PPRD, it is commonly mistaken as juvenile rheumatoid arthritis, however there is no inflammatory process going on in PPRD.

\section{REFERENCE:}

[1] NIH, US National Library of Medicine, Genetics Home Reference, Your Guide to Understanding Genetic Conditions

Acknowledgements: Prof. Tahira Nishtar, Consultant Radiologist, Lady Reading Hospital, Medical teaching Institution, Peshawar, Pakistan

Disclosure of Interest: None declared

DOI: 10.1136/annrheumdis-2018-eular.4376

\section{AB1098 EARLY PROSTHESIS IMPLANTATION IS POSSIBLE IN PATIENTS AFFECTED BY JUVENILE IDIOPATHIC ARTHRITIS, TREATED WITH BIOLOGICS: A MONOCENTRIC EXPERIENCE OF 160 PROSTHESIS FROM THE LAST TWENTY YEARS}

I. Pontikaki ${ }^{1}$, M. Truzzi ${ }^{2}$, T. Ubiali ${ }^{3}$, L.M. Argolini ${ }^{3}$, S. De Martinis ${ }^{2}$, F. Campanaro ${ }^{3}$, R. Viganò ${ }^{2}{ }^{1}$ Unit Of Pediatric Rheumatology-Department Of Rheum; ${ }^{2}$ Surgery of Rheumatic diseases SC; ${ }^{3}$ Rheumatology, Gaetano Pini Institute, Milan, Italy

Background: The main reasons for prosthesis implantation in a young patient are post-traumatic osteoarthritis, congenital dysplasia and autoimmune diseases involving joints, like Juvenile Idiopathic Arthritis (JIA). Often, related to particular anatomic conditions and severe grade of deformity, there may be a need for special (custom made or revision) components of prosthesis. Biologic therapy in severe, refractory JIA has permitted to obtain a better control of the disease so as to procede with prosthesis implantations (hip, knee, ankle).

Objectives: The aim of the study was to present a monocentric experience of a transitional care centre for JIA and the outcome of early prosthesis implantation in patients treated with biologics.

Methods: 160 prosthesis implantation (72 Hip arthroprosthesis, 71 Knee arthroprosthesis and 17 Ankle arthroprosthesis) were performed beetween 1999 and 2017. It was defined a wash-out period from the biologic therapy depending on the half-life of the medication. The survival of the implant was evaluated for a period of 10 years. We evaluated the different type of implants and it was proposed a radiographic classification for every type of implant.

Results: All patients included in the study were treated with biologics. A long term analysis of the following ten years of follow-up proved an average survival of $95.5 \%$ of the prosthesis and good results in term of function and comfort for the patients. Complications in $2 \%$ (two trochanter detachment, two sepsis and one peri-operative haemorrhage).

Conclusions: Prosthesis implantation for JIA patients is a complicated and difficult procedure in comparison with the traditional approach used in patients affected by osteoarthritis. This is related to the management of the biologic therapy, the low quality of the bone, the remarkable stiffness and deformity of the joints. Long-term results were good, even in patients with severe arthritis. There was a drastic reduction of articular pain and an improvement of functionality. Prosthesis implantation in patients with active disease and mild or bad response to the biologics had a worse outcome. The use of not cement-retained implants doesn't influence the long-term survival at ten years, similar to that of the adult patients affected by osteoarthritis.

Disclosure of Interest: None declared

DOI: 10.1136/annrheumdis-2018-eular.6789

\section{AB1099 AN AUDIT ON THE SCREENING GUIDELINES FOR UVEITIS IN CHILDREN WITH JUVENILE IDIOPATHIC ARTHRITIS WITHIN THE ROYAL HOSPITAL FOR CHILDREN, GLASGOW}

J. Waddell ${ }^{1}$, E. Parmar ${ }^{1}$, J. Gardner-Medwin ${ }^{2} .{ }^{1}$ School of Medicine; ${ }^{2}$ Department of Rheumatology, University of Glasgow, Glasgow, UK

Background: Juvenile Idiopathic Arthritis (JIA) defines many arthropathies occurring in children which persist for at least 2 weeks. All JIA patients are at risk of developing uveitis, an inflammatory condition of the eye which poses a risk to visual impairment. The British Society of Paediatric and Adolescent Rheumatology outline guidelines for the screening of these patients. Given the time since publication, an audit on the adherence to said guidelines, as well as patient outcomes, was conducted.
Objectives: Our aim was to identify adherence to the screening guidelines within the RHC, Glasgow; and to what extent adherence to these guidelines prevented the occurrence of uveitis. We aimed to identify areas which could be improved within the Glasgow service itself, as well as providing data for the revision of the guidelines.

Methods: We performed a clinical audit of all JIA patients diagnosed between 1st January 2008 and 31st December 2017, analysing the frequency and adherence of appointments, as well as medication use. Data was gathered from patient medical files and collected into a database for analysis.

Results: 97 of 115 JIA patients entered the screening programme. 72 patients had their initial eye screen within the appointed guidelines of 6 weeks, and 13 of the patients were examined under anaesthetic, with a mean time to examination of 3.31 weeks $(0-7.14)$.

15 patients were seen according to the two-monthly guidelines for the first 6 months of diagnosis. Following this 6 month period, it is suggested patients are screened every three to four-months. 463 out of $641(72.2 \%)$ appointments met this guideline.

After stopping immunosuppressive therapy, it is advised to screen at two-monthly intervals. 97 patients were treated with immunosuppressants, with 10 patients stopping whilst still in the screening service. 9 continued to be seen on a three to four-month basis as before, 1 patient was not screened at all, but no patients were screened according to the guidelines.

Conclusions: Adherence to the screening service could be improved, with $75 \%$ of patients having had their first screen within the guideline criteria, and $72 \%$ seen within the guidelines following the initial 6 months. It seems that improvement mainly needs to be focussed on the methods of appointment rearrangement. There is believed to be a 6 month high-risk period of developing uveitis following cessation of immunosuppressants, thus increased screening is suggested. This was not adhered to well in the Glasgow service, but there was no increased risk of uveitis development found, suggesting the need for alteration to the guidelines.

\section{REFERENCES}

[1] British Society for Paediatric and Adolescent Rheumatology (2006) Guide lines for Screening for Uveitis in Juvenile Idiopathic Arthritis (JIA): BSPAR

[2] Ross E Petty, Taunton R Southwood, Prudence Manners, John Baum, David N Glass, Jose Goldenberg, et al. International League of Associations for Rheumatology classification of juvenile idiopathic arthritis: second revision, Feb 2004 ed.: The Journal of Rheumatology; 2004

[3] Muthappan, V; Feldman, B H. Juvenile Idiopathic Arthritis: Uveitis. American Academy of Opthalmology 2015

Acknowledgements : Thank you to all the staff of both the ophthalmology and rheumatology departments at the Royal Hospital for Children, Glasgow, for their dedication to this service and cooperation with this audit

Disclosure of Interest: None declared

DOI: 10.1136/annrheumdis-2018-eular.7253

\section{AB1100 EPIDEMIOLOGY AND MANAGEMENT PRACTICES FOR CHILDHOOD-ONSET SYSTEMIC LUPUS ERYTHEMATOSUS PATIENTS: A SURVEY IN LATIN AMERICA}

J.C. Ferreira ${ }^{1}$, V.C. Trindade ${ }^{1}$, G. Espada ${ }^{2}$, Z. Morel $^{3}$, E. Bonfa ${ }^{4}$, C. SaadMagalhães ${ }^{5}$, C.A. Silva ${ }^{1} .{ }^{1}$ Pediatric Rheumatology Division, Children's Institute, Hospital das Clinicas HCFMUSP, Faculdade de Medicina, Universidade de Sao Paulo, São Paulo, Brazil; ${ }^{2}$ Pediatric Rheumatology Division, Hospital de Niños Dr Ricardo Gutierrez, Buenos Aires, Argentina; ${ }^{3}$ Pediatric Rheumatology Division, Pediatric Service, Hospital de Clinicas, Universidad Nacional De Asuncion, Asucion, Paraguay; ${ }^{4}$ Division of Rheumatology, Hospital das Clinicas HCFMUSP, Faculdade de Medicina, Universidade de São Paulo, São Paulo; ${ }^{5}$ Pediatric Rheumatology Division, São Paulo State University (UNESP) - Faculdade de Medicina de Botucatu, Botucatu, Brazil

Background: Two groups have reported data focused on epidemiology, clinical and laboratorial features of childhood-onset systemic lupus erythematosus (cSLE) patients in Latin America (LA): BRAC-SLE (Brazilian Childhood-onse SLE Registry Group) and GLADEL (Grupo Latino Americano De Estudio de Lupus). However, to the best of our knowledge, epidemiology and management of cSLE based on LA Paediatric Rheumatologists (LAPR) were not carried out. Objectives: Therefore, the objective of the present cross-sectional survey study was to assess LAPR reports of cSLE patients regarding epidemiology, classification criteria, disease activity and other instruments used in clinical practices, laboratory and other exams availability, general supportive care, drugs availability infections, non-live vaccines, issues observed in adolescents, reproductive health issues and transition-focused program to adult care. 